\title{
O social sob o "tacão de ferro" da política econômica do período 2003-2006 ${ }^{1}$
}

\author{
Rosa Maria Marques ${ }^{2}$ \\ Áquilas Mendes ${ }^{3}$
}

Um fato é indiscutível: [....] previu e descreveu o regime fascista como o resultado irresistível da derrota da revolução proletária. (Trotsky, ao comentar, em 1937, o livro de Jack London, O tacão de ferro, escrito em 1907). ${ }^{4}$

\section{Resumo}

O artigo reflete sobre o impacto da continuidade da política econômica condizente com o novo padrão de acumulação capitalista internacional, sob a dominância do capital financeiro, nos principais ramos da Seguridade Social. Destaca a adoção do regime de metas de inflação e a busca de elevados superávits primários; descreve os principais resultados da economia brasileira e trata do impacto dessa opção sobre o financiamento da Previdência Social e do Sistema Único de Saúde SUS. De forma específica, evidencia que o resultante dessa política - baixo crescimento, manutenção de elevadas taxas de juros, precarização do mercado de trabalho, redução do gasto público - compromete a plena aplicação dos princípios do SUS. Apesar disso, alguns avanços são apontados, como o crescimento da cobertura do Programa de Saúde da Família.

Palavras-chave: Brasil - Política econômica; Brasil - Política e Governo - 2003- ; Silva, Luis Inácio Lula da, 1945- ; Previdência Social; Sistema Único de Saúde (SUS).

\section{Abstract \\ The social policy under the "Iron Heel" of economic policy in the period of 2003-2006}

The article discusses the impact of economic policy maintanence in accordance with the new pattern of international capitalist accumulation under financial capital dominance in main Social Security areas. It analyses the adoption of inflation target system and the achievement of high fiscal primary results; describes the main Brazilian economic results and examine the impact of this particular option on social security with a focus on the financial system of the Unified Health System (SUS). In a specific way, it argues that this policy outcome - low economic growth, high interest rates, unstable work market, reduction in social expenditure - compromises an effective application of the SUS principles. However, some advances have been pointed out, for instance, the increase of Family Health Program coverage.

Key words: Brazil - Economic policy; Brazil - Politics and government; Silva, Luis Inácio Lula da, 1945- ; Social security; Unified Health System (SUS).

JEL I00, I10, I18.

(1) Trabalho recebido em agosto de 2007 e aprovado em junho de 2008.

(2) Professora titular do Departamento de Economia e do Programa de Pós-graduação em Economia Política, e coordenadora do Grupo de Pesquisa Políticas para o Desenvolvimento Humano da Pontifícia Universidade Católica de São Paulo (PUC-SP), São Paulo, SP, Brasil. E-mail: rosamkmarques@ gmail.com.

(3) Professor Doutor do Departamento de Economia da PUC-SP e presidente da Associação Brasileira de Economia da Saúde, São Paulo, SP, Brasil. E-mail: infocogeae@ pucsp.br.

(4) Ver Trotsky (s.d.).

Economia e Sociedade, Campinas, v. 18, n. 3 (37), p. 567-582, dez. 2009. 


\section{Introdução}

À primeira vista, pode parecer abusivo ao leitor apresentar essa epígrafe em um artigo que trata de como a política macroeconômica do período 2003-2006 determinou as condições de financiamento de dois importantes ramos da Seguridade Social: a Previdência e a Saúde. Contudo, a idéia defendida por alguns de que estejamos vivendo sob a égide do fascismo ${ }^{5}$ não é aqui compartilhada, posto que, pelo menos historicamente, essa palavra cheia de conteúdo pressupõe um apoio formidável das classes médias e do então chamado lumpemproletariado.

Não há dúvida de que a relação de forças estabelecida a partir dos anos $1980^{6}$ garantiu o retorno da finança, que passou a dominar e a determinar a forma e o conteúdo da acumulação capitalista (Chesnais, 2006). O retorno da dominância da forma mais fetichizada do capital, num quadro de relações geopolíticas distintas das do final do século XIX e início do século XX, com a participação efetiva da China no mercado mundial, não só coloca os trabalhadores frente à concorrência internacional como impõe limites muito estreitos aos Estados para a adoção de políticas econômicas que fujam à lógica do capital financeiro insaciável ${ }^{7}$ (Chesnais, 2006; Mampaey; Serfati, 2005). Com essa afirmação não queremos dizer que não exista opção fora do quadro geral da mundialização financeirizada. Essas opções, contudo, parciais ou não, precisam enfrentar os determinantes mais gerais que aprisionam e delimitam as políticas fiscais e monetárias dos Estados, colocando-as a serviço do capital financeiro internacional.

A epígrafe se insere no contexto do artigo para lembrar que um dos componentes da retomada da liberdade do capital - à frente, o financeiro, abrindo portas para os demais - foi devida às derrotas infringidas aos movimentos dos trabalhadores, entre as quais são emblemáticas as impostas aos aeroviários americanos e aos mineiros ingleses, como mencionadas na nota 4 deste artigo.

É a partir desse referencial mais amplo que se procura discutir de que forma a política macroeconômica do Executivo influenciou o financiamento de dois importantes ramos da Seguridade Social: a Previdência e a Saúde. Em geral, o acompanhamento das tensões entre a área econômica e os ministérios responsáveis pela aplicação das políticas nesses ramos - evidentes na época em que a Lei de Diretrizes Orçamentária foi elaborada - restringe-se em destacar o tamanho do

(5) Essa concepção está presente principalmente nos artigos e documentos de membros do partido comunista francês, embora não seja exclusiva aos mesmos. Exemplo disso pode ser encontrado no pensamento de Remy Herrera, investigador do CNRS, UMR 8595 Matisse, da Université de Paris 1 Panthéon - Sorbonne. (Conferir Herrera, 2003).

(6) Chesnais (2006) defende que após a derrota da greve dos aeroviários, nos Estados Unidos, e dos mineiros, na Inglaterra, os trabalhadores ficaram na defensiva, não conseguindo se opor a medidas de liberalização de todos os tipos, desde o mercado de trabalho à desregulamentação bancária, entre outros.

(7) A hipótese da insaciabilidade da finança é feita por Chesnais (2005). 
déficit da Previdência (questionado por muitos ${ }^{8}$ ). Procura também demonstrar como, mais uma vez, a equipe econômica busca introduzir, como se fossem de responsabilidade da saúde pública, gastos que não têm correlação nenhuma com as ações e serviços contemplados pelo SUS.

Compreendendo que é preciso ir além dessas constatações e denúncias embora sem desmerecê-las, por serem fundamentais na reversão das tentativas que ocorreram durante o período em análise, como se verá adiante, -o artigo procura, num primeiro momento, esclarecer quais são os pilares da política econômica do governo, e descrever, ainda que brevemente, os resultados dessa política. A segunda parte destaca o impacto desses resultados sobre as receitas da Previdência Social e discute como os fundamentos da política econômica se concretizam em proposições que visam a alterar o quadro legal de vinculação de receitas para a Seguridade Social e o amplo consenso construído em relação ao financiamento do SUS.

Constata-se que a política econômica subordina o social no país e que se pode, de fato, unificar a luta pela retomada dos princípios do SUS com a de um crescimento sustentável, com distribuição de renda e riqueza. Entre os economistas, em geral, verifica-se certa naturalidade em relação a essa subordinação. Na verdade, não há, nesse sentido, nada de natural: trata-se, antes de tudo, de uma escolha política.

\section{A política econômica do governo 2003-2006 ${ }^{9}$}

Desde o início do governo de Luiz Inácio Lula da Silva, ficou claro que, em matéria de política econômica, o governo, ao invés de implementar uma transição para um novo modelo, defendida durante a campanha eleitoral, não só manteve a política macroeconômica do segundo mandato de Fernando Henrique Cardoso - FHC, como a aprofundou. Esse posicionamento fica evidente na manutenção do compromisso de promover o superávit fiscal primário, comentado a seguir. Concordam com essa interpretação vários economistas, entre eles Paulani e Pato (2005), Sicsú e Maringoni (2005) e Bellluzzo (2008).

Em linhas gerais, a política macroeconômica foi fundamentada no regime de metas de inflação, na elevação do superávit primário e na manutenção do regime de câmbio flutuante. No 'regime de metas de inflação', de origem neoclássica, o nível de inflação constitui o principal objetivo a ser atingido, de forma que todas as demais variáveis econômicas a ela devem se subordinar.

(8) Entre os autores que questionam tal posição destacam-se, além da Anfip (2007), Werneck Vianna (2003), Gentil (2007; 2007a), Andrade (2007), Passarinho (2007)., entre outros

(9) Esta parte do artigo e a próxima beneficiaram-se largamente dos estudos de Sanchez et al. (2006) e de Marques e Nakatani (2007). Seu conteúdo, no entanto, foi ampliado e atualizado. 
Assim, sempre que os diretores do Banco Central - Bacen - consideravam que havia uma tendência de a inflação superar a meta fixada, elevava-se a taxa básica de juros (taxa Selic, determinada pelo Comitê de Política Monetária do Bacen), para, dessa forma, deprimir a demanda agregada.

Esse procedimento explica os ciclos de aumento e de redução da taxa de juros vivenciados nos últimos anos. Segundo os relatórios do Banco Central, ${ }^{10}$ no início do governo, frente à tendência altista dos preços, a taxa de juros foi elevada para 25,5\% em janeiro e 26,5\% em fevereiro de 2003. Já partir de junho, com a inflação sob controle, houve uma redução gradual até atingir $16 \%$ em abril de 2004. No entanto, a partir de setembro do mesmo ano, novos aumentos da taxa básica de juros ocorreriam até alcançar 19,75\% em maio, permanecendo nesse patamar até setembro, quando teve início uma nova rodada de reduções. Em dezembro de 2006, a taxa básica de juros chegou a 12,77\%. Apesar da queda acentuada em relação a fevereiro de 2003, essa taxa é extremamente alta para qualquer padrão internacional que se adote.

Em relação ao 'superávit primário', medida de esforço fiscal que visa o pagamento do serviço da dívida, adotado no governo FHC no momento da negociação com o Fundo Monetário Internacional - FMI - houve um aumento de 4,25\% do Produto Interno Bruto PIB - por livre iniciativa da área econômica no ano de 2003. ${ }^{11}$ Durante o governo anterior, esse esforço girou em torno de 3,5\% do PIB, quando o acordado com o FMI havia sido de 3,75\%. Para os anos seguintes, embora a meta não tenha sido formalmente ampliada, o superávit primário ficou em cerca de 4,6\% do PIB em 2004, de 4,8\% em 2005 e de 4,2\% em 2006.

Apesar desse esforço, a dívida mobiliária federal (títulos públicos fora do Bacen) continuou a aumentar: de R 623 bilhões em 2002, fechou 2005 com R\$ 980 bilhões. Em 2006 atingiu R \$1.093,5 bilhões (46\% do PIB). Segundo o Banco Central, a elevação de 0,6 ponto percentual do PIB refletiu, por um lado, a incorporação de juros de $\mathrm{R} \$ 142,4$ bilhões e, por outro lado, resgates líquidos totais de $\mathrm{R} \$ 26,4$ bilhões e o efeito financeiro de R 2,2 bilhões decorrente da apreciação do real frente ao dólar.

Já a dívida líquida do setor público não financeiro, de 55,5\% do PIB em dezembro de 2002, caiu para 46,5\% em dezembro de 2005 e, em dezembro de 2006, para 44,9\% (R\$ 1.067,4 bilhões) do PIB. Essa queda deveu-se especialmente à revalorização do real, que contribuiu tanto para reduzir a dívida

(10) Os dados aqui apresentados foram, com exceção da informação da nota seguinte, todos obtidos através do Banco Central.

(11) Esse aumento foi anunciado em 28 de fevereiro, mediante a Carta de Intenção enviada ao FMI (Ministério da Fazenda, 2003). Para sua efetivação, o Executivo promoveu cortes no orçamento da União de $\mathrm{R} \$ 14,1$ bilhões, o que reduziu a disponibilidade dos ministérios da área social em 12,44\%. 
externa pública como para diminuir a parcela da dívida interna corrigida pela variação cambial. Além disso, os resultados derivados da redução do gasto público foram em parte anulados pela elevação do peso da conta juros provocada pelo aumento e/ou manutenção da alta taxa básica de juros. Dessa forma, os juros nominais devidos pelo setor público, que eram de $8,5 \%$ do PIB em 2002, já bem elevados, aumentaram para 9,3\% do PIB em 2003, mas fecharam 2005 com $8,12 \%$. A diferença entre esses percentuais e os do superávit primário resultou em 'rolagem' de parte dos juros devidos.

Em outras palavras, ao atrelar os juros básicos à meta inflacionária, o governo impediu que sua política fiscal restritiva fosse plenamente eficaz. A combinação do esforço fiscal com as elevadas taxas de juros resultou em baixo crescimento econômico, aumento das rendas dos detentores de riqueza financeira e contínua pressão sobre os gastos sociais, como se verá adiante.

A manutenção do 'regime de câmbio flutuante', por sua vez, resultou em extrema valorização do real, sem que as compras de dólares realizadas pelo Bacen tenham conseguido alterar essa situação. Assim, à parte os primeiros meses do período 2003-2007, o câmbio registrou quedas contínuas.

\section{Os principais resultados econômicos}

No período em estudo, a evolução do PIB seguiu sua trajetória anterior, o que indica a dificuldade da economia brasileira em crescer de forma continuada no quadro dos marcos da política macroeconômica implementada: expansão de apenas 1,1\% em 2003, de 5,7\% em 2004, de 2,9\% em 2005 e de 3,7\% em 2006. Esses percentuais aqui apresentados seguem a nova metodologia adotada pelo IBGE, que confere mais peso ao setor serviços, em consonância com as recomendações das Nações Unidas e de outros órgãos internacionais. Essa nova metodologia implica, necessariamente, a alteração de outros indicadores associados ao PIB. Nesse texto, contudo, preferiu-se manter os valores originais acima, pois, mais do que os números em si, o que importa analisar é sua evolução.

Nesses anos, o crescimento, embora pequeno, do PIB foi principalmente fundado na expansão das exportações que, apesar da valorização do real, aumentaram significativamente. Segundo o Banco Central, em 2005, por exemplo, o setor agropecuário obteve um crescimento de somente $0,8 \%$, a indústria 2,5\% e os serviços 2,0\%. Em relação à despesa, o consumo das famílias cresceu 3,1\%, a formação bruta do capital fixo, 1,6\%, as importações, 9,5\% e o consumo do governo, 1,6\%. A expansão das exportações, por outro lado, foi de 11,6\%. Dessa forma, houve um aumento da dependência do país com relação à performance do 
resto do mundo, principalmente à da China, demandante de commodities. Além disso, diversos economistas, passaram a argumentar que o aumento da participação relativa de produtos com baixo valor adicionado na pauta de exportação configura certa 'reprimarização' dessa mesma pauta. ${ }^{12}$

Os produtos básicos que representavam, em 2000, 22,8\% do valor total das exportações tiveram sua participação elevada para 29,3\% em 2005. Já a contribuição dos produtos semimanufaturados e dos manufaturados tiveram uma redução de $15,4 \%$ para $13,5 \%$ e de $59 \%$ para $55,1 \%$ no mesmo período, respectivamente. ${ }^{13}$ Soma-se a esse movimento de intensificação da participação dos produtos básicos no total das exportações o fato de que parte dos manufaturados apresenta baixa ou média intensidade tecnológica, o que dá um sentido mais amplo à utilização do termo 'reprimarização'. Em 2006 essa tendência se manteve.

O mau desempenho econômico ocorrido no primeiro ano do governo Lula provocou, de acordo com o Instituto Brasileiro de Geografia e Economia (IBGE), uma redução de $12,6 \%$ do rendimento médio habitual ${ }^{14}$ real do trabalhador brasileiro em relação a 2002. Essa redução foi observada em todas as categorias de ocupação, apesar de as mais organizadas terem firmado acordos de reajuste salarial favoráveis no segundo semestre, quando o nível de atividade se recuperou um pouco.

Nesse primeiro ano, ainda, a taxa média de desemprego aberto das cinco regiões metropolitanas, calculada pelo IBGE, registrou aumento de 12,3\%; em relação a 11,7\% em 2002. Em 2004, embora a economia tenha crescido 4,9\%, o rendimento médio real de trabalhadores ocupados recuou mais $0,7 \%$, embora a taxa média de desemprego para o mesmo ano tenha caído para 11,5\%. Em 2005, o rendimento médio habitual real apresentou uma pequena recuperação, crescendo $2 \%$ em relação ao ano anterior. Esse desempenho, contudo, não atingiu os trabalhadores com carteira assinada, que sofreram redução de $0,8 \%$ em seu rendimento médio habitual real (em 2004 havia aumentado 0,3\% e, em 2003, reduzido em 4,9\%). Nesse ano a taxa média de desemprego continuou a cair, registrando 9,8\%. Em 2006, no entanto, a taxa de desemprego atingiu 10\%, embora o emprego tenha crescido mais entre os trabalhadores com carteira assinada e o rendimento médio habitual real tenha registrado um crescimento de $4,3 \%$, segundo o IBGE, para as cinco regiões metropolitanas pesquisadas.

(12) Ver Belluzzo e Carneiro (2003).

(13) O total não atinge $100 \%$ devido a operações especiais.

(14) No cálculo do rendimento habitual não são consideradas horas extras, atrasados, férias, etc. 
Em relação ao rendimento, vale salientar que, com variações, houve um pequeno ganho ao longo do período em análise (de um rendimento médio real de pessoas ocupadas de $\mathrm{R} \$ 1.108,74$ em janeiro de 2003 para $\mathrm{R} \$ 1.390,61 \mathrm{em}$ dezembro de 2006) (Ipeadata, 2008; IBGE. 2006). Os registros, no entanto, apontam que houve um aprofundamento do processo de concentração de trabalhadores ocupados nas faixas de renda mais baixas (Tabela 1). Em 2002, esse percentual era de 87,6\% (IBGE, 2002). Evidentemente, o aumento real observado no salário mínimo contribuiu para que essa concentração ocorresse.

Tabela 1

Empregados de 10 anos ou mais de idade no trabalho principal da semana de referência, por classe de rendimento - Brasil

\begin{tabular}{l|r|r|r|r}
\hline & 2003 & \multicolumn{1}{|c|}{2004} & \multicolumn{1}{c}{2005} & \multicolumn{1}{c}{2006} \\
\hline Total & 100,00 & 100,00 & 100,00 & 100,00 \\
\hline Até 1/2 & 5,82 & 5,15 & 5,54 & 5,38 \\
\hline Mais de 1/2 a 1 & 18,97 & 19,04 & 21,38 & 22,16 \\
\hline Mais de 1 a 2 salários mínimos & 34,27 & 36,93 & 38,11 & 39,6 \\
\hline Mais de 2 a 3 salários mínimos & 16,8 & 13,89 & 13,74 & 13,06 \\
\hline Mais de 3 a 5 salários mínimos & 12,5 & 13,43 & 11,12 & 9,31 \\
\hline Até 5 salários mínimos & 88,36 & 88,44 & 89,89 & 89,51 \\
\hline Mais de 5 a 10 salários mínimos & 6,68 & 6,85 & 6,32 & 6,57 \\
\hline Mais de 10 a 20 salários mínimos & 2,71 & 2,63 & 2,09 & 1,99 \\
\hline Mais de 20 salários mínimos & 1,00 & 0,7 & 0,59 & 0,54 \\
\hline Sem rendimento & 0,13 & 0,1 & 0,11 & 0,11 \\
\hline Sem declaração & 1,12 & 1,29 & 1,00 & 1,29 \\
\hline
\end{tabular}

Fonte: IBGE. Pesquisa Nacional por Amostra de Domicílios (2005).

Embora o salário mínimo não seja reflexo direto da política macroeconômica adotada, e sim resultado de uma decisão política de governo, o fato de o piso dos benefícios previdenciários e o Benefício de Prestação Continuada serem por ele definidos, justifica seu destaque nesta parte do artigo. Vale lembrar que se o governo não cumpriu sua promessa de campanha de dobrar seu valor real, promoveu um aumento de $35,03 \%$ em seu poder aquisitivo, quando se compara a situação de dezembro de 2002 com a de dezembro de 2006 (Ipeadata, 2008; IBGE, 2006).

Um outro elemento importante que deve ser registrado, e que tem reflexos sobre a Seguridade Social, diz respeito ao grau de precarização das relações de trabalho. Conforme se pode ver na Tabela 2, a situação em 2006 melhorou em relação a 2005, embora a maioria dos trabalhadores ocupados com 10 anos ou mais na semana de referência e no trabalho principal, não contribuísse para qualquer instituto de previdência. 
Rosa Maria Marques / Áquilas Mendes

Tabela 2

Pessoas de 10 anos ou mais de idade, ocupadas na semana de referência, por contribuição para instituto de previdência no trabalho principal - Brasil

\begin{tabular}{l|c|c|c|c}
\hline & 2003 & 2004 & 2005 & 2006 \\
\hline Total & 100,00 & 100,00 & 100,00 & 100,00 \\
\hline Contribuintes & 46,16 & 46,31 & 47,18 & 48,56 \\
\hline Não contribuintes & 53,84 & 53,68 & 52,82 & 51,44 \\
\hline Sem declaração & 0 & 0 & & - \\
\hline
\end{tabular}

Fonte: IBGE. Pesquisa Nacional por Amostra de Domicílios (2005).

\section{Os impactos da política econômica sobre a seguridade social e o SUS}

O primeiro aspecto destacável entre a relação da política macroeconômica do governo e a 'Seguridade Social' foi a extensão da vigência da Desvinculação das Receitas da União - DRU $-{ }^{15}$ para 2007. No momento da criação desse dispositivo, em 1994, durante o primeiro governo FHC, houve franca oposição dos setores comprometidos com a Seguridade Social; o Partido dos Trabalhadores, no entanto, fechou questão contra sua aprovação no Congresso Nacional. Por isso, os setores que apoiaram a eleição de Lula em 2002 esperavam que o novo governo desse fim a esse dispositivo. Contudo, não foi o que aconteceu: no bojo da reforma tributária encaminhada pelo governo e aprovada em 2003 ficou definida sua vigência até 2007.

Em 2004, o volume de recursos desviados da Seguridade Social totalizou $\mathrm{R} \$ 24,9$ bilhões, o que correspondeu a $77,5 \%$ do gasto realizado pelo governo federal em saúde nesse ano. Em 2005, foram desviados R\$32,129 bilhões, isto é, 93\% do gasto em ações e serviços de saúde efetuados pelo Ministério da Saúde (ANFIP, 2005). Desnecessário dizer que os recursos desvinculados mediante a DRU alimentam a formação do superávit primário, descrito na parte 1 deste artigo.

Para o segundo mandato do governo Lula, as expectativas são ainda mais desanimadoras, pois integrantes de seu governo, vinculados à esfera econômica, falam em aumentar o percentual da desvinculação para cerca de $40 \%$. Reeleito Lula, essa proposta tem perdido força na mídia, pois agora é a vez de se discutir uma nova reforma da Previdência Social e de continuar adiando a regulamentação da Emenda Constitucional n. 29, como detalhado adiante.

Em relação à 'Previdência Social' do Regime Geral - RGPS, o impacto da economia se fez sentir principalmente sobre a receita das contribuições. Essas, resultantes da aplicação de alíquotas sobre a massa salarial dos ocupados junto ao

(15) Permite que $20 \%$ das receitas de impostos e contribuições sejam livremente alocados pelo governo federal, inclusive para pagamento dos juros da dívida. Na época de sua criação, em 1994, chamava-se Fundo Social de Emergência, em 1997 foi renomeado como Fundo de Estabilização Fiscal e, em 2000, finalmente, seu nome passa a expressar seu verdadeiro conteúdo - Desvinculação das Receitas da União. 
mercado de trabalho formal, sentiram o peso da informalidade e o elevado desemprego, principalmente nos anos em que a economia apresentou os piores resultados, estando longe de evoluir de acordo com as taxas de crescimento de décadas anteriores. Mesmo assim, o total da arrecadação líquida, depois de ter decrescido em 2003 com relação ao ano anterior, aumentou 9,3\% em 2004 e 9,4\% em 2005. ${ }^{16}$

Segundo o Ministério da Previdência Social, ${ }^{17}$ a expansão observada nesse último ano deveu-se ao comportamento favorável do mercado de trabalho formal, à ação da Secretaria da Receita Previdenciária, principalmente na recuperação de créditos junto a devedores, e à elevação do teto da contribuição. Em 2006, novamente a receita previdenciária apresentou crescimento, agora auxiliada pelo crescimento formal observado na economia. Nesse ano, a arrecadação líquida foi de $\mathrm{R} \$ 172,7$ bilhões, algo em torno de 5,9\% do PIB.

Ainda em relação à Previdência, o governo promoveu, em seu primeiro ano de mandato, uma reforma no regime pertinente aos funcionários públicos. Essa reforma retirou direitos dos servidores, ao introduzir um teto para o valor do benefício (anteriormente o valor da aposentadoria correspondia ao valor do provento, não sofrendo redução).

Além disso, o governo implantou uma contribuição sobre o valor da aposentadoria para os servidores e para os trabalhadores do setor privado, segurados pelo RGPS. Essa contribuição, que fere o princípio previdenciário de reciprocidade, somente incide a partir de um determinado valor de aposentadoria. À introdução de um valor máximo para a aposentadoria dos funcionários públicos, foi associada a criação de fundos de pensão, que, assim como para os trabalhadores do setor privado, podem ser organizados e administrados por sindicatos e centrais sindicais (Marques; Mendes, 2004). Até o momento, contudo, eles não foram regulamentados, pois a legislação necessária não foi ainda objeto de discussão e aprovação. Vale ressaltar que essas medidas foram de encontro com a tradição e o posicionamento dos representantes do PT em momentos anteriores, quando da reforma da Previdência encaminhada por FHC.

Evidentemente, como o crescimento da arrecadação líquida das contribuições não foi suficiente para dar conta da defasagem existente entre as receitas e as despesas previdenciárias, membros do governo, logo depois da reeleição de Lula, têm firmado um diálogo intenso com a mídia sobre um possível encaminhamento de novo projeto de reforma da Previdência, desta vez alterando

(16) A arrecadação líquida foi de R\$ 92,3 bilhões em 2003; R\$ 100,9 bilhões em 2004 e R \$ 110,4 bilhões em 2005, a valores de dezembro de 2005. Disponível em: www.mpas.gov.br/pg_secundarias/previdencia_social_10.asp e http://www.fundacaoanfip.org.br/bancodedados. Acesso em: dez. 2006 e ago. 2007.

(17) Ver nota 11. 
as condições de acesso à aposentadoria e o valor do benefício tanto para os trabalhadores do setor privado da economia como para os funcionários públicos.

Em relação 'à saúde pública', os principais impactos da política econômica em seu financiamento ocorreram no momento da elaboração da proposta orçamentária e no não encaminhamento da regulamentação da Emenda Constitucional n. 29 (Brasil, 2000). A importância assumida pela proposta orçamentária deveu-se ao fato de a meta relativa ao superávit primário, além de se traduzir em contingenciamentos, resultar em diferentes tentativas de redução dos gastos, inclusive os sociais.

No caso da saúde pública, a equipe econômica tentou introduzir itens de despesa que não são considerados gastos em saúde no orçamento do Ministério da Saúde. Entre esses itens figuraram, entre outros, o pagamento de juros e a despesa com a aposentadoria dos ex-funcionários desse ministério. Essas tentativas não foram a termo, embora estivessem sendo apoiadas por toda a área econômica do governo , pois as entidades da área da saúde - o Fórum da Reforma Sanitária (Abrasco, Cebes, Abres, Rede Unida e Ampasa)-, o Conselho Nacional de Saúde e a Frente Parlamentar da Saúde rapidamente se mobilizaram e fizeram o governo recuar.

\section{Tentativas de redução do orçamento do Ministério da Saúde}

A Lei de Diretrizes Orçamentárias - LDO - para o orçamento de 2004 previa que os Encargos Previdenciários da União - EPU, o serviço da dívida e os recursos alocados no Fundo de Combate e Erradicação da Pobreza fossem contabilizados como gastos do Sistema Único de Saúde do Ministério da Saúde. Contudo, a forte reação contrária do Conselho Nacional de Saúde e da Frente Parlamentar da Saúde determinou que o Poder Executivo enviasse mensagem ao Congresso Nacional estabelecendo que, para efeito das ações em saúde, seriam deduzidos o EPU e o serviço da dívida. Em relação ao Fundo da Pobreza a mensagem era omissa. Essa omissão resultaria na redução de R 3.571 milhões no orçamento do SUS do Ministério da Saúde (Relatório da Comissão de Orçamento e Financiamento do Conselho Nacional de Saúde, 2003).

Apesar de diversos e intensos debates terem ocorrido entre entidades vinculadas ao SUS e o Ministério do Planejamento, nada foi modificado sobre essa questão. Somente após o parecer do Ministério Público Federal, contrariando a decisão presidencial e solicitando ao presidente Lula a retirada do veto ao dispositivo que esclarecia que os recursos do Fundo de Combate e Erradicação da Pobreza não poderiam ser contabilizados como gastos em saúde, sob pena do orçamento aprovado vir a ser considerado inconstitucional, o governo recuou. Foi assim que a Lei n. 10.777, de 25 de novembro de 2003, contempla, no parágrafo 
segundo do artigo 59, que o EPU, o serviço da dívida e as despesas do MS com o Fundo de Combate e Erradicação da Pobreza não fossem considerados como ações e serviços públicos de saúde.

Da mesma forma, o projeto de Lei de Diretrizes Orçamentárias (LDO) para o orçamento de 2006, encaminhado pelo governo federal à Câmara, previa que as despesas com assistência médico-hospitalar dos militares e seus dependentes (sistema fechado) fossem consideradas no cálculo de ações e serviços de saúde. Caso fossem consideradas, os recursos destinados ao Ministério da Saúde seriam diminuídos em cerca de $\mathrm{R} \$ 500$ milhões. Frente à declaração pública do MS, repudiando essa interpretação, e frente à mobilização das entidades da saúde, o governo federal foi obrigado a recuar, reformulando sua proposta.

\section{A vinculação da Emenda Constitucional 29 é objeto da atenção da área econômica}

Em fins de 2003, o Executivo encaminhou documento referente ao novo acordo com o Fundo Monetário Internacional, ${ }^{18}$ comunicando sua intenção de preparar um estudo referente às implicações das vinculações constitucionais das despesas sociais — saúde e educação — sobre as receitas dos orçamentos da União, dos estados e dos municípios. A justificativa apoiava-se na idéia de que a flexibilização da alocação dos recursos públicos poderia assegurar uma trajetória de crescimento ao país. ${ }^{19}$ No âmbito do SUS, a intenção do governo era tirar do Ministério da Saúde a obrigação de gastar, em relação ao ano anterior, valor igual acrescido da variação nominal do PIB; dos estados, $12 \%$ de sua receita de impostos, compreendidas as transferências constitucionais; e, dos municípios, $15 \%$, tal como define a EC 29. ${ }^{20}$

Quando Lula foi eleito pela primeira vez, pensava-se que, finalmente, não haveria obstáculos para que saísse a regulamentação da EC 29. Afinal, os temas tratados por ela haviam sido objeto de longa discussão entre representantes dos conselhos municipais e estaduais, do Conselho Nacional de Saúde, o Ministério da Saúde e os Tribunais de Contas dos Estados e Municípios.

(18) O documento referente ao novo acordo com o FMI é dirigido ao seu diretor executivo, Köhler (Ministério da Fazenda, 2003).

(19) Ministério da Fazenda (2003, p. 3).

(20) A Proposta de Emenda Constitucional 169, vinculando recursos para a saúde pública, foi elaborada pelos deputados Eduardo Jorge e Waldir Pires. A motivação foi o fato de o Ministério da Saúde, em 1993, não ter recebido os recursos previstos no orçamento da União, de origem nas contribuições de empregados e empregadores, o que levou à ocorrência do seu primeiro empréstimo junto ao Fundo de Amparo ao Trabalhador FAT (PEC 169). Depois disso, várias outras propostas de vinculação foram elaboradas e discutidas no Congresso Nacional, mas somente em 2000 foi aprovada a emenda constitucional (EC 29). De acordo com a EC 29, a União deveria alocar, para o primeiro ano, pelo menos $5 \%$ a mais do que foi empenhado no orçamento do período anterior, e, para os seguintes, o valor apurado no ano anterior corrigido pela variação do PIB nominal. 
Entre os principais itens do projeto de regulamentação da EC 29, destacam-se dois. Em primeiro lugar, salienta-se a modificação da base de cálculo da vinculação dos recursos da União, passando do valor apurado no ano anterior corrigido pela variação do PIB nominal para $10 \%$, no mínimo, da sua Receita Corrente Bruta, o que resultaria em aumento expressivo de recursos para a área da saúde.

No campo da aplicação da EC 29, o único dado positivo provém dos municípios, pois sua grande maioria vem respeitando o determinado. Em 2005, apenas 153 municípios, dos 5.343 que informaram ao MS, deixaram de cumpri-la. A responsabilidade pela execução da política do SUS em nível local responde ao pacto firmado, subjacente à Emenda.

Espera-se que, com a regulamentação da EC 29, os gastos com ações e serviços de saúde passem da atual faixa de US\$ 150/200 per capita, para a de US\$ 250/300, ainda insuficientes para a viabilização do SUS, mas apontando, junto aos demais avanços que constam da regulamentação, para novo patamar de esperanças, confiabilidades e pactuações de otimização dos gastos entre as três esferas de governo e delas com a sociedade.

Em segundo lugar, cabe destacar que o Projeto de Lei Complementar 01/2003 (PLP 01/2003 - que regulamenta a EC 29) trata da definição das despesas que devem ser consideradas como ações e serviços de saúde e daquelas que não se enquadram nesse conceito. Várias são as formas de onerar o SUS, mediante iniciativas dos governos federal e estaduais, incluindo, nos Fundos de Saúde, gastos como saneamento, alimentação, planos privados de servidores, pagamento de inativos e outros nos estados. Segundo Santos (2007), essas formas referem-se às famigeradas "caronas".

O resultado das discussões de todas as entidades na área da saúde em relação a esse projeto de regulamentação da Emenda Constitucional 29 foi expressão de um grande consenso visto como absolutamente necessário para garantir o financiamento e o comprometimento das diferentes esferas de governo na construção do SUS. É por isso que, durante o primeiro ano de governo, a fim de finalizar os encaminhamentos pró-regulamentação da EC 29, foram realizados, em Brasília, mais dois seminários promovidos pela Câmara Técnica do Sistema de Informações sobre Orçamentos Públicos em Saúde - SIOPS e pela Comissão para Elaboração de Proposta de Lei Complementar (PLC) do Ministério da Saúde, onde foi intensa a discussão das entidades presentes. ${ }^{21}$

(21) Conasems; Procuradoria Geral da República; Banco do Brasil; representante da Associação dos Membros dos Tribunais de Contas; Conselho Federal de Contabilidade; assessoria do Deputado Roberto Gouveia; assessoria do Deputado Guilherme Menezes - PT/Bahia; IBGE/Depto. de Contas Nacionais; técnicos do SIOPS; Secretaria Gestão Participativa/MS; STN; técnicos do Departamento de Economia da Saúde/MS; assessoria da bancada do PT na Câmara Federal. 
Contudo, para surpresa de muitos, a regulamentação da EC 29 não se constituiu prioridade do governo. Mesmo assim, em abril de 2003, fruto da ação da Frente Parlamentar da Saúde, passou a integrar a pauta do Congresso, à espera de sua votação. Passado mais de um ano, em que pese os esforços do MS, da Frente, do Conass e do Conasems, entre outros, nada mudou em relação à regulamentação da EC 29.

A não prioridade da matéria expressa, na verdade, a tensão existente entre a área da saúde e a área econômica do governo. A primeira, compromissada com a trajetória histórica do SUS, e, por isso, preocupada em garantir seu financiamento e em definir as ações e serviços de saúde pública; e a segunda, restringida por uma política econômica fundada em metas de inflação e na geração de superávits primários. Nessa situação, a regulamentação das vinculações previstas na EC 29 é vista como um retrocesso, pois impõe despesas mínimas e comprometimentos mínimos de receitas, o que estaria contrariando o esforço de geração de superávit. Ao mesmo tempo, no entender da equipe econômica, isso limitaria o poder discricionário do governo, que não poderia alocar os recursos de acordo com seus interesses mais imediatos. Dessa forma, o gasto mínimo definido e a vinculação mínima de recursos estariam respondendo a interesses que independeriam do governo de ocasião, expressando compromissos de longo prazo.

\section{Avanços da saúde pública}

Apesar das restrições impostas pelo marco macroeconômico, houve avanços na área da saúde pública no período 2003-2006. Nos três primeiros anos, a taxa de cobertura do Programa Saúde da Família, com relação ao total da população brasileira, aumentou significativamente: 35,7\% (2003); 39\% (2004) e $43,04 \%$ (2005). No último ano do governo FHC, esse percentual era de $32,4 \%$. O grau de cobertura varia muito entre as regiões e os municípios: em 2004, por exemplo, enquanto no Nordeste era de 54,85\%, na Região Sudeste atingia apenas $29 \%$. $^{22}$

Não se pode dizer, entretanto, que esse programa tenha sido (e seja) propriamente uma marca do Executivo no período em análise, pois seu início data de 1994, embora somente em 1998 tenha se consolidado como uma política prioritária do Ministério da Saúde. Poder-se-ia argumentar, contudo, que o fato de o governo ter dado continuidade a seu processo de implantação é, em si, digno de nota, indicando seu grau de compromisso com relação a um programa considerado prioritário por todas as instâncias participativas do SUS.

Entre os programas iniciados durante o período em análise destacam-se o Brasil Sorridente e o programa Farmácia Popular. O primeiro, integrante da

(22) Ver o site do Ministério da Saúde. Disponível em: www.saude.gov.br. Acesso em: 10 dez. 2006. 
Política de Saúde Bucal, propiciou que a cobertura do atendimento da saúde bucal aumentasse de 17,5\% em 2002, para 33,7\% em 2005. Já o programa Farmácia Popular consiste em oferecer medicamentos essenciais a baixo custo. Em 14 de dezembro de 2006, o Ministério da Saúde (MS) inaugurava a 243 ${ }^{\text {a }}$ Farmácia Popular do país. Dessa forma, segundo informação do site do MS, esse programa atingia "60 milhões de brasileiros, em 193 municípios de 24 estados e do Distrito Federal". Desde o lançamento do programa, em junho de 2004, foram realizados mais de 6,5 milhões de atendimentos e fornecidos mais de 40 milhões de produtos. Essa iniciativa não está, contudo, isenta de críticas. Há quem considere que a cobrança pelo medicamento fere o princípio da gratuidade, presente no SUS.

\section{Considerações finais}

Para a Seguridade Social, em geral, e para o SUS, em particular, a forte possibilidade de que a política econômica do segundo governo Lula tenha como base os mesmos fundamentos ${ }^{23}$ da que foi desenvolvida em seu primeiro mandato é mais do que preocupante. Isso porque, do ponto de vista das políticas sustentadas pelos diferentes ramos da Seguridade Social, especialmente para a Previdência e para a Saúde, não terá o enfretamento das mesmas restrições e problemas. No caso da Previdência, a crescente defasagem entre as receitas de contribuições e as despesas com benefícios (embora a Seguridade como um todo apresente um superávit também crescente, mas que é desconhecido do grande público e esquecido pela mídia) é fonte de argumentos para justificar a implantação de uma reforma mais abrangente que resulte na redução dos gastos futuros com benefícios.

Em relação à Seguridade como um todo, a intenção de aumentar o percentual das contribuições na composição da DRU - antes de significar mais um passo no sentido da destruição da idéia de um orçamento para a Seguridade pode resultar na sua inviabilidade e/ou na perda de sentido material. Em relação ao SUS, a luta incessante dos últimos anos pela defesa de níveis mínimos de recursos que, a bem da verdade, não começou no período $2003-2006,{ }^{24}$ pode se converter em crescente descompromisso dos diferentes níveis de governo com a saúde pública. Frente à não regulamentação da EC 29 e ao efeito demonstração dado pela União, dificilmente o MS, o Conselho Nacional de Saúde, o Conselho Nacional das Secretarias Municipais de Saúde - Conasems - e o Conselho Nacional dos Secretários Estaduais de Saúde - Conass - terão força para fazer valer o pacto que gerou a proposta da EC 29.

Esse possível descompromisso, num país onde a desigualdade de renda é

uma das piores do mundo, o desemprego é elevado e o mercado de trabalho está

(23) Destaca-se que aqui a referência aos fundamentos e não ao desempenho da economia em relação ao PIB.

(24) Para detalhes, ver Marques e Mendes (2006). 
majoritariamente na informalidade - a ponto de que quando se fala em precarização supõe-se que a realidade dessa maioria pode vir a se estender ao conjunto dos ocupados - justifica em parte o uso da epígrafe deste artigo. As ações que o atual governo tem realizado em direção aos segmentos de renda mais baixos, tais como o Programa Bolsa Família, e a ênfase no resgate do poder aquisitivo do salário mínimo são bem-vindos, mas não alteram os determinantes estruturais da pobreza brasileira. Pelo contrário, no momento em que sua política econômica não se diferencia da ditada pelos interesses do capital financeiro internacional, à pobreza secular brasileira soma-se outra, decorrente de um regime de acumulação de baixo crescimento e elevados níveis de rentabilidade (Husson, 2006).

\section{Referências bibliográficas}

ANDRADE, E. I. G. Componentes econômico, demográfico e institucional na Previdência Social brasileira. In: SEMINÁRIO COMO INCLUIR OS EXCLUÍDOS? Contribuição ao Debate sobre a Previdência Social no Brasil. Campinas: Instituto de Economia da Unicamp, 2007. Disponível em: www.eco.unicamp.br/pesquisa/CESIT/index.php.

ANFIP - Associação Nacional dos Auditores Fiscais da Previdência Social. Análise da Seguridade Social em 2004, 2005 e 2006. Disponível em: http://www.anfip.org.br. Acesso em: 12 dez. 2006.

BANCO CENTRAL DO BRASIL. Boletim do BC - Relatório anual, vários anos. Disponível em: http://www.bcb.gov.br/economia. Acesso em: 07 jul. 2007.

BELLUZZO L. G. Entrevista concedida aos jornalistas Valéria Nader e José Damião Vasconcelos. In: Correio da Cidadania, 27 de março de 2008. Disponível em: http://www.correiocidadania.com.br/content/view/1602/9/. Acesso em: 17 abr. 2008.

; CARNEIRO, R.. Globalização e integração perversa. Política Econômica em Foco, Campinas, v. 1, p. 1-11, maio/ago. 2003.

BRASIL. Constituição, 1988. Emenda Constitucional 29, 13 de setembro de 2000. Altera os arts. 34, 35, 156, 160, 167 e 198 da Constituição Federal e acrescenta artigo ao Ato das Disposições Constitucionais Transitórias para assegurar os recursos mínimos para o financiamento das ações e serviços públicos de saúde. DOU, 13 set. 2000.

CHESNAIS, F. La preeminence de la finance. In: LA FINANCE capitaliste. Paris: Presse Universitaires de France, 2006.

GENTIL, D. L. A política fiscal e a falsa crise do sistema de seguridade social no Brasil: análise financeira do período recente. In: SICSÚ, João (Org.). Arrecadação (de onde vem?) e gastos públicos (para onde vão). São Paulo: Boitempo, 2007.

O mito do déficit da Previdência e o orçamento da seguridade social. Análise Financeira do período 1995-2006. In: SEMINÁRIO COMO INCLUIR OS EXCLUÍDOS? Contribuição ao Debate sobre a Previdência Social no Brasil. Campinas: Instituto de Economia da Unicamp, 2007a. Disponível em: www.eco.unicamp.br/pesquisa/CESIT/index.php.

HERRERA, R. Sob o véu da mundialização. Crise, imperialismo e guerra. Revista da Sociedade Brasileira de Economia Política, n. 13, dez. 2003. 
Rosa Maria Marques / Áquilas Mendes

HUSSON, M. Finance, hyper-concurrence et reproduction du capital. In: LA FINANCE capitaliste. Paris: Presse Universitaires de France, 2006.

INSTITUTO BRASILEIRO DE GEOGRAFIA E ESTATÍSTICA. Pesquisa Nacional por Amostra de Domicílios (PNAD-2003). Disponível em: www.ibge.gov.br. Acesso em: abr. 2005.

Pesquisa Mensal de Emprego, 2002. Disponível em: http://www.ibge.gov.br/home/presidencia/noticias/24012003pme.shtm. Acesso em: dez. 2006.

IPEADATA. Rendimento médio real efetivamente recebido pelas pessoas, de 10 anos ou mais de idade, ocupadas, por Regiões Metropolitanas. Disponível em: http://www.ibge.gov.br/home/presidencia/noticias/24012003pme.shtm. Acesso em: $17 \mathrm{de}$ abr. 2008.

MAMPAEY, L.; SERFATI, P. Os grupos armamentistas e os mercados financeiros rumo a um compromisso "guerra sem limites"?. In: CHESNAIS, F. (Org.). A finança mundializada. São Paulo: Boitempo, 2005.

MARQUES, R. M. Democracia y universalidad: discutiendo las condiciones de aplicar tales conceptos a las acciones y servicios de salud pública de Brasil. Revista Bienestar y Política Social, Ciudad de México: Universidad Ibero-Americana, v. 2, n. 1, primer semestre 2006.

; MENDES, A. O Governo Lula e a contra-reforma previdenciária. São Paulo em Perspectiva, São Paulo, v.18, p. 3-15, set./ jul. 2004.

; NAKATANI, P. A política econômica do governo Lula: como mudar para ficar no mesmo. Revista Tiers Monde, Paris: Sorbonne, n. 189. No prelo.

MINISTÉRIO DA FAZENDA. Carta de intenção referente ao novo acordo. Brasília, 2003. Disponível em: http://www.fazenda.gov.br. Acesso em: 30 set. 2004.

PASSARINHO, Paulo. Previdência social pública: um serviço universal ao cidadão brasileiro. In: SICSÚ, João (Org.). Arrecadação (de onde vem?) e gastos públicos (para onde vão). São Paulo: Boitempo, 2007.

PAULANI, L.; PATO, C. G. Investimentos e servidão financeira: o Brasil do último quarto de século. In: De PAULA, João Antônio (Org.). Adeus ao desenvolvimento. Belo Horizonte: Autêntica, 2005.

SÁNCHEZ, F. et al. A política econômica da esquerda latino-americana no governo: o caso do Brasil. Projeto Madison 2, 2006. Mimeografado.

SANTOS, Nelson R. Regulamentação do financiamento do Sistema Único de Saúde (Da E.C. n. 29): por que debater e aprovar já. Campinas, abr. 2007. Mimeografado.

SICSÚ, J.; MARINGONI, G. Avaliando o desempenho do PT e do governo Lula. Quem perdeu? Quem ganhou? In: De PAULA, João Antônio (Org.). Adeus ao desenvolvimento. Belo Horizonte: Autêntica, 2005.

TROTSKY, L. Lettre à Joan London. In: LONDON, J. Le talon de fer. Paris. Librairie Hachette, s.d.

WERNECK VIANNA, M. L. T. Reforma da Previdência. Seminário de Pesquisa. Rio de Janeiro: Instituto de Economia - UFRJ, jun. 2003. 